\title{
Anticoagulation for three versus six months in patients with deep vein thrombosis or pulmonary embolism, or both: randomised trial
}

\author{
I A Campbell, consultant chest physician, ${ }^{1}$ D P Bentley, consultant haematologist, ${ }^{1}$ R J Prescott, professor \\ of medical statistics, ${ }^{2}$ P A Routledge, professor of clinical pharmacology, ${ }^{1}$ H G M Shetty, consultant \\ physician, ${ }^{3}$ I J Williamson, consultant physician ${ }^{4}$
}

'Llandough Hospital, Llandough, Cardiff CF64 2XX

${ }^{2}$ Department of Public Health Sciences, University of Edinburgh, Edinburgh

${ }^{3}$ University Hospital of Wales, Cardiff

${ }^{4}$ Royal Gwent Hospital, Newport, Gwent

Correspondence to: I A Campbell ian.campbell@cardiffandvale. wales.nhs.uk

doi: 10.1136/bmi.39098.583356.55

\section{ABSTRACT}

Objective To determine the optimum duration of oral anticoagulant therapy after an episode of deep vein thrombosis or pulmonary embolism, or both.

Design Multicentre, prospective, randomised study with follow-up for one year.

Setting 46 hospitals in United Kingdom.

Participants Patients aged $\geq 18$ with deep vein thrombosis or pulmonary embolism, or both.

Interventions Three $(n=369)$ or six months $(n=380)$ of anticoagulation with heparin for five days accompanied and followed by warfarin, with a target international normalised ratio of 2.0-3.5.

Main outcome measures Death from deep vein thrombosis or pulmonary embolism; failure to resolve, extension, recurrence of during treatment; recurrence after treatment; and major haemorrhage during treatment.

Results In the patients allocated to three months' treatment two died from deep vein thrombosis or pulmonary embolism during or after treatment, compared with three in the six month group. During treatment deep vein thrombosis or pulmonary embolism failed to resolve, extended, or recurred in six patients in the three month group without fatal consequences, compared with 10 in the six month group. After treatment there were 23 nonfatal recurrences in the three month group and 16 in the six month group. Fatal and non-fatal deep vein thrombosis or pulmonary embolism during treatment, and after treatment thus occurred in $31(8 \%)$ of those who had received three months' anticoagulation compared with 29 (8\%) of those who had received six months' $(P=0.80,95 \%$ confidence interval for difference $-3.1 \%$ to $4.7 \%)$. There were no fatal haemorrhages during treatment but there were eight major haemorrhages in those treated for six months and none in those treated for three months ( $P=0.008,-3.5 \%$ to $-0.7 \%)$. Thus $31(8 \%)$ of the patients receiving three months' anticoagulation experienced adverse outcomes as a result of deep vein thrombosis or pulmonary embolism or its treatment compared with 35 (9\%) of those receiving six months' $(P=0.79,-4.9 \%$ to $3.2 \%)$.
Conclusion For patients in the UK with deep vein thrombosis or pulmonary embolism and no known risk factors for recurrence, there seems to be little, if any, advantage in increasing the duration of anticoagulation from three to six months. Any possible advantage would be small and would need to be judged against the increased risk of haemorrhage associated with the longer duration of treatment with warfarin.

Trial registration Clinical Trials NCT00365950.

\section{INTRODUCTION}

In 1960 Barritt and Jordan established that anticoagulation reduced the risk of death and of recurrent embolism in patients with pulmonary embolism, ${ }^{1}$ a conclusion subsequently supported by retrospective studies from Oxford ${ }^{2}$ and the United States. ${ }^{3}$ Treatment regimens now consist of heparin for four to five days, ${ }^{4-6}$ with anticoagulation maintained thereafter by warfarin. In the 1970 s and 1980s three relatively small randomised trials suggested that there was no benefit in anticoagulation for more than three to six weeks ${ }^{7-9}$ but practice in United Kingdom and abroad continued to vary widely. ${ }^{10}$ In 1992, the British Thoracic Society published the results of a large multicentre prospective study, which indicated that because the outcome with three months' anticoagulation was significantly better than with one month, three months' anticoagulation should be given to patients with pulmonary venous thromboembolism (first episode or no episode for the previous three years). ${ }^{112}$ This recommendation has not been universally accepted, with authoritative sources in the UK, North America, and Europe continuing to recommend six months or more. ${ }^{13-16}$ To obtain further evidence, the British Thoracic Society designed and conducted another multicentre study to compare the outcomes of two durations of anticoagulation, three and six months, with warfarin after initial heparin therapy.

For those centres not already routinely using low molecular weight heparin, an expanded design was used to compare low molecular weight heparin with 
unfractionated heparin in terms of outcome during treatment outcome after the end of anticoagulation, and duration of inpatient stay. Too few patients $(n=22)$ were entered into this randomisation for meaningful comparions of these outcomes and so we used their results solely in the comparisons of three months versus six months of anticoagulation.

\section{METHODS}

\section{Patients}

Eligible patients were those aged $\geq 18$ with suspected or proved deep vein thrombosis or pulmonary embolism, or both, whom the clinician intended to treat with anticoagulant. We encouraged confirmation of diagnosis with ultrasound, radioisotope, venographic, angiographic, or other objective tests but patients managed without the aid of such tests were accepted for the trial. Categories of definite, probable (high or moderate probability), low probability, or negative were taken from the reports of the results.

Several factors or conditions excluded patients from entry. These were deep vein thrombosis or pulmonary embolism deemed so severe by the clinician as to require thrombolysis or pulmonary embolectomy; neoplasia diagnosed or requiring treatment, or both, within the previous three years; pregnancy; deep vein thrombosis or pulmonary embolism in the preceding three years; known polycythaemia, thrombocythaemia, antithrombin III deficiency, lupus anticoagulant, homozygous factor $\mathrm{V}$ Leiden, protein $\mathrm{C}$ or protein $\mathrm{S}$ deficiency, or other similar predisposing haematological disorders; any condition that would result in prolonged or continuous immobility or confinement to bed, such as advanced multiple sclerosis or orthopaedic problems of the lower limbs; previous allergy to heparin or warfarin; requirement for long term anticoagulant therapy; and inability to give informed consent.

\section{Design}

Patients were randomised to three or six months of warfarin, the clinicians being asked to start warfarin on day one of the scheduled five days of heparin. Participating physicians used international normalised ratios to monitor anticoagulation with warfarin according to a standardised protocol. ${ }^{17}$ The aim was to achieve ratios between 2.0 and 3.5.

Within each centre randomisation was by permuted blocks of eight through a series of numbered envelopes kept at a central point in each hospital or unit. Each envelope also contained an entry card to be posted to the coordinator as notification of entry. On receipt of that card the coordinator sent a form to the clinician, confirming the allocated treatment and requesting further details of the patient. This form also contained a section for the clinician to notify the coordinator of alteration of diagnosis or discontinuation of anticoagulation, or both: if a patient was found to fulfil any of the criteria for exclusion, that patient was removed from the analysis before we had any knowledge of the outcome of the study.

The individual clinicians were responsible for decisions about inpatient or outpatient management. For purposes of the trial, physicians were asked to arrange follow-up appointments at three, six, and 12 months from the date of entry. Brief review forms were sent to the clinician a fortnight or so before each follow-up date for completion and return to the coordinator. The forms requested information on failure of resolution (swelling of the $\operatorname{leg}(\mathrm{s})$ or pain or tenderness that did not settle down during treatment), extension or recurrence of deep vein thrombosis or pulmonary embolism, results of international normalised ratios, dates of start and completion of therapy with heparin and with warfarin, and adverse events. Clinicians were asked to confirm suspected failure of resolution, extension, or recurrence by radiological or ultrasonic imaging, or both.

Predetermined primary adverse outcomes were death from deep vein thrombosis or pulmonary embolism, failure during treatment (failure to resolve, extension, recurrence during treatment), recurrence after the end of treatment, and major haemorrhage during treatment. Patients experiencing any of the above were grouped together under the heading of "adverse outcome," and we reported this as a further point of comparison between the groups.

We graded anticoagulation as good if the international normalised ratios were between 2.0 and 3.5 on at least two thirds of occasions, moderate if within that range on a third but less than two thirds of occasions, or poor if within that range for less than a third of occasions, as used previously. ${ }^{11}$ For patients in the six month group we applied these gradings separately for the first three months and for the second three months.

Haemorrhage was defined as major if the treating clinician deemed transfusion necessary, if the haemoglobin concentration fell by $20 \mathrm{~g} / \mathrm{l}$, if bleeding was intracranial or retroperitoneal, or if it was sufficiently serious for the clinician to discontinue anticoagulation.

Each participant gave written informed consent before entry into the trial, and clinicians used standardised letters to inform the patients' general practitioners.

\section{Statistical analysis}

We calculated that we would need 2400 patients to have $80 \%$ power to detect a difference, significant at the $5 \%$ level, between recurrence rates of $6 \%$ and $9 \%$. The coordinator and the coordinating physician checked all entry forms on receipt to ensure the patients' eligibility. After exclusion of ineligible patients we analysed the results by standard statistical methods according to the randomisation to define a full analysis population. ${ }^{18}$

\section{Type of anticoagulant}

We offered centres a supply of a low molecular weight heparin (dalteparin) to use in the trial. In centres 


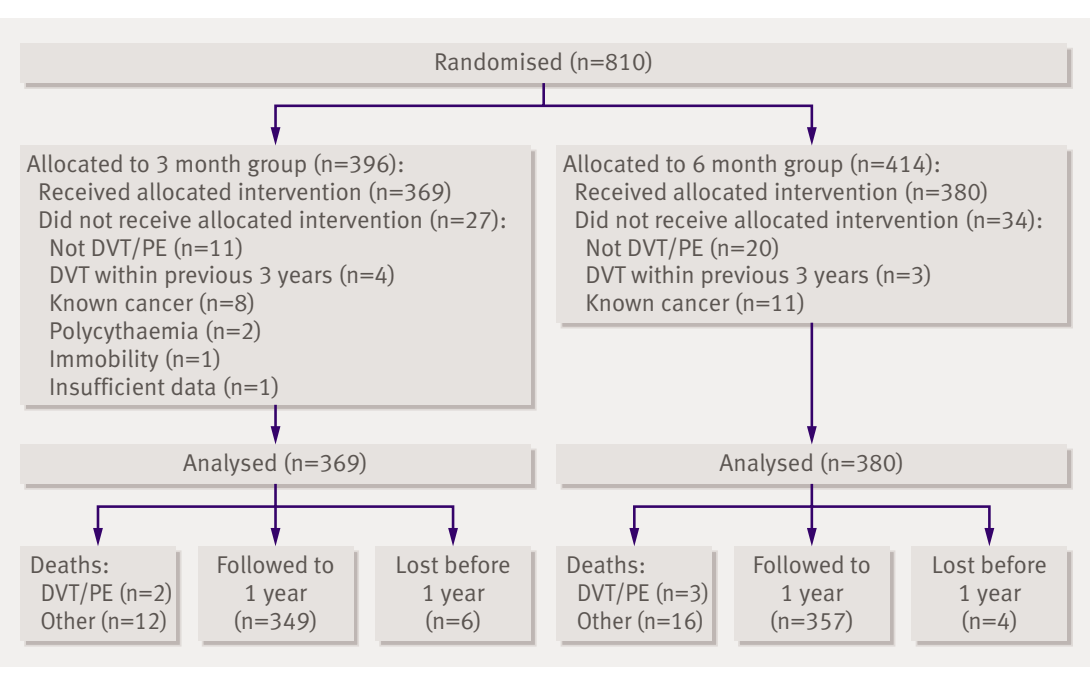

Fig 1 | Flow of patients through trial (DVT=deep vein thrombosis; PE=pulmonary embolism)

already using another low molecular weight heparin we asked participating clinicians to change to dalteparin, but inability or unwillingness to do so did not exclude their patients from the trial. The standard oral anticoagulant was warfarin, but clinicians could use an alternative coumarin if necessary.

\section{RESULTS}

From mid-September 1999 to the end of December 2002, 137 consultants from 46 hospitals (37 in England, four in Scotland, four in Wales, and one in Northern Ireland) entered 810 patients. Sixty one patients were excluded from analysis because they did not satisfy the entry criteria (27 in the three month group, 34 in the six month group), leaving 369 patients randomised to three months of treatment and 380 to treatment for six months (fig 1). These two groups were comparable over a broad range of characteristics, though a slightly higher proportion of men and of patients with pulmonary embolism were allocated to six months' treatment (table 1). Diagnosis was confirmed as definite in $91 \%$ of those receiving three months' anticoagulation and $92 \%$ of those receiving six months' and as probable in $6 \%$ and $6 \%$, respectively, an overall frequency of definite or probable of $97 \%$.

Among those for whom we had the data, heparin was given for three to seven days in $74 \%$ of patients in the three month group and 77\% of those in the six month group (table 2). The minority of patients who received heparin for less than five days did so because the target international normalised ratio had been achieved early. Among those who received more than five days' heparin the usual reason was that the target ratio had not been achieved, though in a few patients an intervening weekend seemed to be the only reason. If we allowed three weeks either side of three months and six weeks either side of six months and considered those in whom durations were known (322 of three month group and 348 of six month group), 259 (80\%) of those allocated to three months' treatment and 307 $(88 \%)$ of those allocated six months received treatment with warfarin as per protocol. In those with shorter or longer durations, variations were because of errors by physicians or general practitioners, misunderstanding in patients, and rescheduling of follow-up clinics.

Control of warfarin therapy was good or moderate in most patients, but at the three month follow-up 42 (13\%) of 335 patients in the three month group with sufficient data were graded as poorly controlled, as were $37(11 \%)$ of 340 in the six month group. Control improved between three and six months, and among those with sufficient data $(\mathrm{n}=313)$, only $11(4 \%)$ were graded as poorly controlled. Two patients (both in the six month group) could not tolerate warfarin and were changed to alternative coumarins.

Table 3 shows the main outcomes. During treatment four patients died from deep vein thrombosis or pulmonary embolism (one in the three month group, three in the six month group), and one patient in the

Table 1 | Characteristics of treatment groups at entry to trial. Figures are numbers (percentages) unless stated otherwise

\begin{tabular}{|c|c|c|c|}
\hline & Three month group $(n=369)$ & Six month group $(n=380)$ & Total $(n=749)$ \\
\hline Mean (SD) age (years) & $59.0(15.7)$ & $58.5(15.0)$ & $58.7(15.4)$ \\
\hline \multicolumn{4}{|l|}{ Patients } \\
\hline Men & $183(50)$ & $215(57)$ & $398(53)$ \\
\hline DVT only & $271(73)$ & $257(68)$ & $528(70)$ \\
\hline PE with or without overt DVT & $98(27)$ & $123(32)$ & $221(30)$ \\
\hline Objective confirmation sought & $365(99)$ & 378 (99) & 743 (99) \\
\hline Confirmed as definite or probable & $356(96)$ & $370(97)$ & $726(97)$ \\
\hline \multicolumn{4}{|l|}{ Underlying causes of DVT/PE } \\
\hline None evident & $155(42)$ & $179(47)$ & $334(45)$ \\
\hline Recent surgery & $44(12)$ & $42(11)$ & $86(11)$ \\
\hline Short term immobility & $79(21)$ & 74 (19) & $153(20)$ \\
\hline DVT/PE >3 years before or family history of DVT/PE, or both & $9(2)$ & $12(3)$ & $21(3)$ \\
\hline Postpartum, contraceptive pill, or HRT & $15(4)$ & $17(4)$ & $32(4)$ \\
\hline Travel & $32(9)$ & $32(8)$ & $64(9)$ \\
\hline Other & $35(9)$ & $24(6)$ & $59(8)$ \\
\hline
\end{tabular}

DVT=deep vein thrombosis; $\mathrm{PE}=$ pulmonary embolism; HRT=hormone replacement therapy. 
Table 2 | Details of treatment in patients with deep vein thrombosis or pulmonary embolism according to length of anticoagulation

\begin{tabular}{|c|c|c|}
\hline & $\begin{array}{l}\text { Three } \\
\text { month } \\
\text { group } \\
(n=369)\end{array}$ & $\begin{array}{c}\text { Six month } \\
\text { group }(n=380)\end{array}$ \\
\hline \multicolumn{3}{|l|}{ Type of heparin: } \\
\hline Dalteparin & 235 & 238 \\
\hline Tinzaparin & 117 & 126 \\
\hline $\begin{array}{l}\text { Other (including unfractionated } \\
\text { heparin) }\end{array}$ & 17 & 15 \\
\hline Not known & 0 & 1 \\
\hline \multicolumn{3}{|l|}{ Duration of heparin (days): } \\
\hline $1-2$ & 25 & 25 \\
\hline 3-7 & 267 & 285 \\
\hline$>7$ & 67 & 61 \\
\hline Not known & 10 & 9 \\
\hline \multicolumn{3}{|l|}{ Duration of warfarin (weeks): } \\
\hline$<9$ & 11 & 7 \\
\hline $9-15$ & 259 & 17 \\
\hline$>15-<18$ & 27 & 5 \\
\hline $18-30$ & 25 & 307 \\
\hline$>30$ & 0 & 12 \\
\hline Not known & 47 & 32 \\
\hline \multicolumn{3}{|l|}{ Warfarin control: } \\
\hline \multicolumn{3}{|l|}{ At $0-3$ months: } \\
\hline Good & 201 & 208 \\
\hline Moderate & 92 & 95 \\
\hline Poor & 42 & 37 \\
\hline Insufficient data & 34 & 40 \\
\hline \multicolumn{3}{|l|}{ At 3-6 months: } \\
\hline Good & - & 227 \\
\hline Moderate & - & 75 \\
\hline Poor & - & 11 \\
\hline Insufficient data & - & 67 \\
\hline
\end{tabular}

three month group died from deep vein thrombosis or pulmonary embolism one month after completing treatment, an overall mortality of $0.7 \%$.

Twelve patients in the three month group and 16 in the six month group died from causes other than deep

Table 3 | Outcome at one year in patients with deep vein thrombosis or pulmonary embolism according to length of anticoagulation

\begin{tabular}{lcc} 
& $\begin{array}{c}\text { Three month group } \\
(\mathrm{n}=369)\end{array}$ & $\begin{array}{c}\text { Six month group } \\
(\mathrm{n}=380)\end{array}$ \\
Deaths from PE during or after treatment & $2(0.5 \%)$ & $3(0.8 \%)$ \\
\hline Deaths from haemorrhage during treatment & 0 & 0 \\
\hline Deaths from known other causes during or after treatment & 12 & $16^{\star}$ \\
\hline Outcome at one year unknown & 6 & 4 \\
\hline Non-fatal extensions, failures of resolution, or recurrences of & $29(8 \%)$ & $26(7 \%)^{*} \dagger$ \\
\hline DVT/PE & 0 & $8(2 \%) \dagger$ \\
\hline Major non-fatal haemorrhages during treatment & $31(8 \%)$ & $35(9 \%)$ \\
\hline Adverse outcome as a result of DVT/PE or its treatment & &
\end{tabular}

$\mathrm{PE}=$ pulmonary embolism; DVT=deep vein thrombosis.

*Includes one patient who died from haemorrhage after end of treatment, having had recurrence of DVT/PE and received further anticoagulation.

†Two patients had non-fatal extension, failure of resolution, or recurrence of DVT/PE as well major non-fatal haemorrhages.

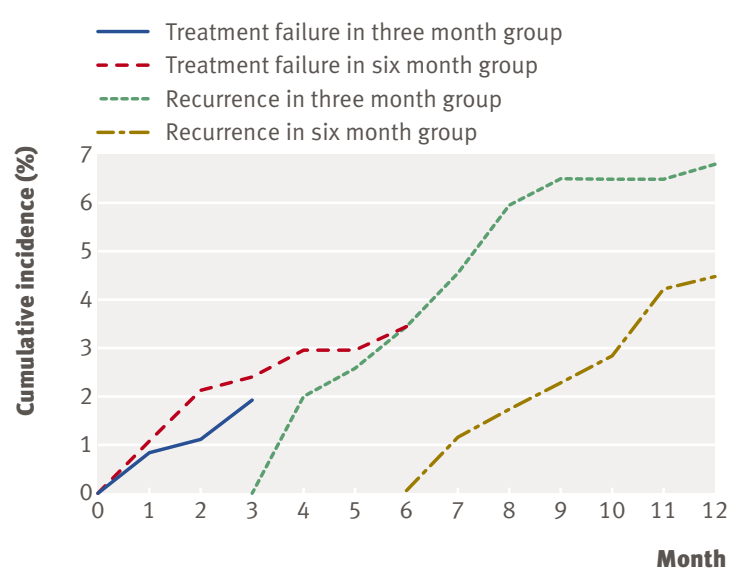

Fig 2 | Cumulative incidence of failure of treatment or recurrence of deep vein thrombosis or pulmonary embolism in the treatment groups

vein thrombosis or pulmonary embolism during and after treatment, one of whom (in the six month group) died at home from an unspecified cerebrovascular event during treatment. For 10 patients (six in the three month group and four in the six month group) we had no information on whether they were alive or had died by the end of their year in the trial. None of these 10 patients had experienced any adverse outcome of deep vein thrombosis or pulmonary embolism or its treatment up to the time they were last seen by their doctors.

In six patients in the three month group and 10 patients in the six month group deep vein thrombosis or pulmonary embolism failed to resolve, extended, or recurred during treatment without fatal consequences. After the end of treatment there were 23 non-fatal recurrences in the three month group and 16 in the six month group. Therefore there were 29 (24, 83\%) were objectively confirmed) non-fatal failures to resolve, recurrences, or extensions during treatment plus recurrences after treatment in the three month group and $26(20,77 \%)$ were objectively confirmed) in the six month group (table 3). Fatal and non-fatal failures during treatment plus recurrences after treatment thus occurred in $31(8.4 \%)$ patients in the three month group and $29(7.6 \%)$ in the six month group $(\mathrm{P}=0.80,95 \%$ confidence interval for difference $-3.1 \%$ to $4.7 \%$ ) (fig 2).

During treatment no one in the three month group experienced major non-fatal haemorrhages, though eight $(2 \%)$ in the six month group did so (one in the second month, two in the third month, and five in the fourth month), one of whom also experienced failure during treatment and one experienced relapse after treatment $(\mathrm{P}=0.008,95 \%$ confidence interval for difference $-3.5 \%$ to $-0.7 \%$ ). None of these occurred when patients were receiving heparin.

Thus all adverse outcomes (deaths from deep vein thrombosis or pulmonary embolism, major haemorrhages during treatment, failures during treatment, and recurrences after treatment) as a result of deep vein thrombosis or pulmonary embolism or its 


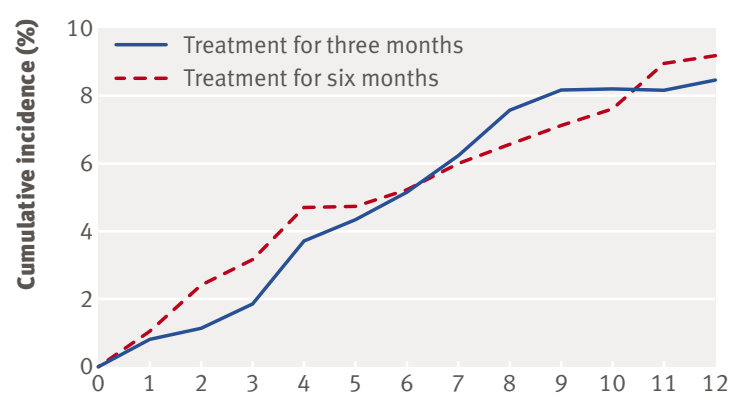

Month

Fig 3 | Cumulative incidence of adverse outcomes in the two treatment groups

treatment occurred in $31(8 \%)$ patients allocated to three months' treatment and $35(9 \%)$ patients allocated to six months' treatment (fig 3$)(\mathrm{P}=0.79,-4.9 \%$ to $3.2 \%)$.

In relation to outcome, there was no interaction between the duration of treatment and the original diagnosis (logistic regression $\mathrm{P}=0.44$ ). Overall, 221 $(30 \%)$ of the 749 patients presented with pulmonary embolism (with or without evidence of deep vein thrombosis) and $22(10 \%)$ of them experienced fatal and non-fatal failures of resolution or recurrences, or both, whereas among the 528 patients who presented with deep vein thrombosis alone there were $38(7 \%)$ fatal and non-fatal failures of resolution or recurrences, or both, during and after treatment $(\mathrm{P}=0.26,-1.8 \%$ to $7.3 \%)$.

The proportions of failures of resolution, extension, or recurrence of deep vein thrombosis or pulmonary embolism were similar in those who had received dalteparin $(35 / 473 ; 7 \%)$, tinzaparin $(22 / 243 ; 9 \%)$, and enoxaparin $(3 / 22 ; 14 \%)\left(\chi^{2}=1.5, \mathrm{df}=2, \mathrm{P}=0.47\right)$.

\section{DISCUSSION}

Outcomes and relevance to practice

In this trial $8 \%$ of patients with deep vein thrombosis or pulmonary embolism experienced fatal and non-fatal failures of resolution, extension, or recurrence during and after three months of anticoagulation. The results were similar in those patients who had received six months' anticoagulation but in this group $2 \%$ experienced major haemorrhages during treatment, whereas none of those treated for three months did. As we conducted the study across a wide range of acute hospitals in the UK, our results are likely to be representative of those that pertain in routine practice.

\section{Comparison with previous studies}

Previous randomised trials that had included at least 100 patients with deep vein thrombosis or pulmonary embolism reported failures during treatment and recurrences after treatment for six months in $9-17 \%$ of patients. ${ }^{7817}$ In 1992 the first British Thoracic Society study, conducted in a similar setting, reported that $8 \%$ of patients who had received three months' anticoagulation experienced failure during treatment or recurrence after end of treatment, or both. ${ }^{11}$ More patients in our study underwent confirmatory investigations at initial presentation than in the previous study $(99 \% v 83 \%)$, with definite confirmation of diagnosis in $97 \%$ v $71 \%$. We were able to establish objective confirmation of non-fatal failures during treatment or relapses after treatment in 80\% compared with $42 \%$ in the earlier study. ${ }^{11}$ Pinede et al directly compared three and six months' treatment and reported an $8 \%$ rate of failure during treatment or recurrence after the end of treatment for both durations of anticoagulation .${ }^{19}$ Schulman et al randomised patients to six weeks' or six months' treatment and reported recurrence rates of $18 \%$ at two years with six weeks' treatment and $9 \%$ with six months' treatment. ${ }^{14}$ When the follow-up in that study was extended to six years, the recurrence rates rose to $28 \%$ in the six week group and $21 \%$ in six month group, leading the authors to conclude that there was a cumulative risk of recurrence of $4-5 \%$ a year after the index event, independent of the initial duration of anticoagulation. ${ }^{20}$ After 10 years of follow-up there was no significant difference between the recurrence rates $\left(31 \%\right.$ and 27\%). ${ }^{21}$ In 2001 and 2003 Agnelli and colleagues published two studies in which they had followed patients for two years: recurrence rates in those receiving three months' treatment varied between $12 \%$ and $16 \%$, compared with $12 \%$ and $17 \%$ in those receiving 12 months' treatment. The authors concluded that for patients with deep vein thrombosis or pulmonary embolism prolonging anticoagulant therapy beyond three months simply delayed recurrence until anticoagulation was stopped..$^{223}$ Kearon et al compared three months' treatment with extended therapy and concluded that patients with a first episode of idiopathic deep vein thrombosis or pulmonary embolism should be treated for longer than three months. ${ }^{24}$ The design of their study did not allow them to say how much longer and in this relatively small study a high proportion (17 of 83) of those assigned to receive placebo after three months had recurrences ( $27 \%$ per patient per year) compared with only one of 79 assigned to receive warfarin $(1.3 \%$ per patient per year, $\mathrm{P}<0.001)$. In addition the rate of major bleeding in the extended treatment group was $3.8 \%$ a year compared with $0 \%$ a year in the three month group. ${ }^{24}$ In our study, at one year the numbers of patients with failure of resolution during treatment and recurrences after the end of anticoagulation were only marginally and non-significantly greater among those who had received three months' treatment rather than six months' treatment (31/369 v29/380).

One year mortality from deep vein thrombosis or pulmonary embolism in previous clinical trials ranged from $0 \%$ to $2.2 \%,{ }^{8914} 1922-24$ the previous study in 1992 reporting a rate of $1 \%,{ }^{11}$ whereas the 1996 and 2000 cohort studies each noted mortality of $0.5 \% .{ }^{2526}$ The $0.7 \%$ rate in the current study is well within this range. In terms of deaths from deep vein thrombosis or pulmonary embolism there was no significant 


\section{WHAT IS ALREADY KNOWN ON THIS TOPIC}

In patients with deep vein thrombosis or pulmonary embolism, or both, anticoagulation with heparin and warfarin reduces mortality and morbidity

Treatment for four to six weeks is usually enough for patients in whom the cause is transient In other instances treatment for three months or more is necessary

\section{WHAT THIS STUDY ADDS}

For patients with deep vein thrombosis or pulmonary embolism in whom there are no persistent risk factors three months' anticoagulation is as effective as six months' treatment and is associated with a lower risk of major bleeding

difference between the two groups $(2 / 369$ in the three month group $v 3 / 380$ in the six month group).

\section{Major haemorrhages}

A meta-analysis published in 2005 suggested that the risk (weighted incidence rate) of major bleeding was similar for patients receiving long term anticoagulation and those on short term regimens. ${ }^{27}$ Our results showed an overall rate of $1 \%$ in the trial as a whole, though the longer regimen of anticoagulation was associated with a $2 \%$ risk of major bleeding over the six month period of treatment. In our study there was only one death that might possibly have been caused by intracranial haemorrhage, a patient who died at home during the fifth month from an unspecified cerebrovascular event while receiving treatment in the six month group. In the clinical trials between 1990 and 2005, deaths from major haemorrhage were reported in $0.1 \%$ to $0.4 \%$ of patients receiving three months' treatment compared with $0.1 \%$ in those receiving six months' treatment. ${ }^{114}{ }^{1922-24}$ In the cohort studies of 1996, 2000, and 2005 the death rate from major haemorrhage was $0.5 \%$ in those receiving three months' anticoagulation..$^{25-28}$

\section{Factors affecting sample size}

Though we achieved a larger sample size than many other trials, it was disappointing relative to our planned sample. The start of the trial was delayed initially by difficulties with obtaining finance. Then, after we obtained permission to do the trial from a multicentre research ethics committee, further difficulties and delays were caused by local committees in several centres. As a result some physicians withdrew from the trial. Furthermore, by the time the intake began many centres that had been willing to participate in the comparison of unfractionated heparin versus low molecular weight heparin had already switched to the routine use of low molecular weight heparin and physicians at those centres were unwilling to randomise patients between the two. All this occurred at a time of steep increase in workload generated by a rise in numbers of emergency medical admissions. These factors combined to reduce the number of patients recruited. The result of the reduction in sample size has been to increase the standard error of the differences for the primary outcome variables between the two periods of anticoagulation to $2 \%$ compared with an expected standard error with the original design of just over $1 \%$.
The observed differences for the primary outcome variables, however, are small, excluding substantial differences in favour of either length of treatment.

\section{Conclusions}

For patients with deep vein thrombosis or pulmonary embolism occurring in circumstances other than the presence of major thrombophilias or other persisting risk factors, our results do not affect the advice previously given in the British Thoracic Society guidelines ${ }^{29}$ In terms of efficacy, three months' anticoagulation was associated with much the same benefit as six months' anticoagulant treatment but the shorter regimen seems to be associated with a lower incidence of haemorrhage during treatment. Further large, well designed trials are needed to establish the optimum duration of anticoagulation in various subgroups, including more studies of the place of d-dimer testing in determining duration. ${ }^{30}$

We thank the 55 lead consultants (S Ansari, P Brown, Ashington; J Barclay, Oldham; C E Bucknall, Glasgow; A L Burton, Preston; I A Campbell, Penarth; S J Connellan, Wolverhampton; A G Davidson, A O’Brien, Southend; G Douglas, Aberdeen; M El-Nazir, Barrow-in-Furness; E N Evans, Darlington; A Fennerty, Harrogate; J Gravil, Paisley; H R Gribbin, Middlesborough; R Harrison, Stockton on Tees; R W Heaton, Huddersfield; N Hodges, Bangor; H Hosker, Keighley; J A Hughes, R Banks, Tunbridge Wells; P D Hughes, Plymouth; A M Hunter, York S Jegarajah, M J Malik, Rochdale; R Jones, H Moudgil, Telford; N P Keaney, I K Taylor, Sunderland; W Kinnear, Nottingham; C Laroche, Bury St Edmunds: N Munro, Durham; S Packham, Margate; E Peel, O A Afalobi, Northshields; T K Rogers, Doncaster; C Roseveare, Southampton; P Ryan, S Rattan, Hereford; S Saboor, Enfield; D Seaton, Ipswich; C Selby, Dunfermline; D R T Shepherd, Belfast; H Shetty, Cardiff; D Spence, Northallerton; S C Stenton, Newcastle; J Turner, T Raza, Bournemouth; J Warren, Harlow; R F Willey, D A Wales, Lancaster and Kendal; I Williamson, Newport; M D Winson, K Toori, Crewe; B Yung, Basildon) and their 83 consultant/staff grade colleagues, junior doctors, nurses, secretaries, and pharmacists for their cooperation. We also thank Diane Wyatt for coordinating the study and Linda Lockerbie of the Medical Statistics Unit, Public Health Sciences, University of Edinburgh, for data entry, checking, and analysis.

Contributors: IAC (chairman and coordinating physician) wrote the first draft of the protocol, which was modified after discussion with all the authors. IAC oversaw data entry and wrote the first draft and final version of the report. RIP supervised data checking and performed the statistical analyses. All authors amended and commented on the report and checked the final draft. British Thoracic Society is guarantor.

Funding: Pharmacia Upjohn (now part of Pfizer) supplied dalteparin free of charge.

Competing interests: None declared.

Ethical approval: Multicentre research ethics committee for Wales.

Participating clinicians informed their local research ethics committees of the approval.

1 Barritt DW, Jordan SC. Anticoagulant drugs in the treatment of pulmonary embolism: a controlled trial. Lancet 1960;i:1309-12.

2 Morrell MT, Truelove SC, Barr A. Pulmonary embolism. BMJ 1963; ii:830-5.

3 Coon WW, Willis PW III, Symons MJ. Assessment of anticoagulation treatment of venous thromboembolism. Ann Surg 1969;170:559-68

4 Schulman S, Lockner D, Bergstrom K, Blomback M. Intensive initial oral anticoagulation and shorter heparin treatment in deep vein thrombosis. Thromb Haemost 1984;52:276-80.

5 Gallus A, Jackaman J, Tillett J, Mills W, Wycherley A. Safety and efficacy of warfarin started early after submassive venous thrombosis or pulmonary embolism. Lancet 1986;ii:1294-96.

6 Hull RD, Raskob GE, Rosenbloom D, Panju AA, Brill-Edwards P, Ginsberg JS, et al. Heparin for 5 days as compared with 10 days in the initial treatment of proximal venous thrombosis. $N$ Engl J Med 1990;322:1260-4 
7 O'Sullivan EF. Duration of anticoagulant therapy in venous thromboembolism. Med J Aust 1972;2:1104-7.

8 Holmgren K, Andersson G, Fagrell B, Johnsson H, Ljunberg B, Nilsson E, et al. One-month versus six-month therapy with oral anticoagulants after symptomatic deep vein thrombosis. Acta Med Scand 1985;218:279-84.

9 Fennerty AG, Dolben J, Thomas P, Backhopuse G, Bentley DP, Campbell IA, et al. A comparison of 3 and 6 week' anticoagulation in the treatment of venous thromboembolism. Clin Lab Haemat 1987;9:17-21.

10 Management of venous thromboembolism. Lancet 1988;i:275-7.

11 Research Committee of the British Thoracic Society. Optimum duration of anticoagulation for deep-vein thrombosis and pulmonary embolism. Lancet 1992;340:873-6.

12 British Thoracic Society. Suspected acute pulmonary embolism: a practical approach. Thorax 1997;52(suppl 4):S1-24.

13 Hirsh J. The optimal duration of anticoagulant therapy for venous thrombosis. N Engl J Med 1995;332:1710-1.

14 Schulman S, Rhedin AS, Lindmarker P, Carlsson A, Larfars G, Nicol P, et al. A comparison of six weeks with six months of oral anticoagulant therapy after a first episode of venous thromboembolism. N Engl J Med 1995;332:1665.

15 Buller HR, Agnelli G, Hull RD, Hyers TM, Prons MH, Raskpb GE, et al. Antithrombotic therapy for venous thromboembolic disease. The Seventh ACCP Conference on Antithrombotic and Thrombolytic Therapy. Chest 2004;126:401-28S.

16 Baglin TP, Keeling DM, Watson HG, for the British Committee fo Standards in Haematology. BSH guidelines on oral anticoagulation (warfarin): third edition-2005 update. Br J Haematol 2005;132:277-85.

17 Fennerty A, Campbell IA, Routledge PA. Anticoagulants in venous thromboembolism. BMJ 1988;297:1285-8.

18 ICH Harmonised Tripartite Guideline. Statistical principles for clinical trials. Stat Med 1999;18:1905-42.

19 Pinede L, Ninet J, Duhaut P, Chaboud S, Demolombe-Rague S, Durieu I, et al. Comparison of 3 and 6 months of oral Anticoagulation after a first episode of proximal venous thrombosis or pulmonary embolism and comparison of 6 and 12 weeks of therapy after Isolated calf deep vein thrombosis. Circulation 2001;103:2453-60.
20 Schulman S. The effect of the duration of anticoagulation and other risk factors on the recurrence of venous thromboembolism. Duration of Anticoagulation Study Group. Wien Med Wochenschr 1999;149:66-9.

21 Schulman S, Lindmarker P, Holmstrom M, Larfars G, Carlsson, Nicol $P$, et al. Post-thrombotic syndrome, recurrence and death 10 years after the first episode of venous thromboembolism treated with warfarin for 6 weeks or 6 months. J Thromb Haemost 2006;4:734-42.

22 Agnelli G, Prandoni P, Santmaria MG, Bagatella P, Iorio A, Bazzan M, et al. Three months versus one year of oral anticoagulant therapy for idiopathic deep venous thrombosis. N Engl Med 2001;345:165-9.

23 Agnelli G, Prandoni P, Becattini C, Silingardi M, Taliani MR, Miccio M, et al. Extended oral anticoagulant therapy after a first episode of pulmonary embolism. Ann Intern Med 2003;139:19-25.

24 Kearon C, Gent M, Hirsh J, Weitz J, Kovacs MJ, Anderson DR, et al. A comparison of three months of anticoagulation with extended anticoagulation for first episode of idiopathic venous thromboembolism. N Engl Med 1999;340:901-7.

25 Prandoni P, Lensing AW, Cogo A, Cuppini S, Villalta S, Caria M, et al. The long-term clinical course of acute deep venous thrombosis. Ann Intern Med 1996;125:1-7.

26 Hansson PO, Sorbo J, Eriksson H. Recurrent venous thromboembolism after deep vein thrombosis. Arch Intern Med 2000;160:769-74.

27 Ost D, Tepper J, Mihara H, Lander O, Heinzer R, Fein A. Duration of anticoagulation following venous thromboembolism: a metaanalysis. JAMA 2005;294:706-15.

28 Bigaroni A, Perrier A, Moerloose P, Perneger T, Bounameaux H. Risk of major bleeding in unselected patients with venous thromboembolism. Blood Coagul Fibrinolysis 2000;11:199-202.

29 British Thoracic Society. Guidelines for the management of suspected acute pulmonary embolism. Thorax 2003;58:470-84.

30 Palareti G, Cosmi B, Legnani C, Tosetto A, Brusi C, lorio A, et al. ddimer testing to determine the duration of anticoagulation. $N$ Engl J Med 2006;355:1780-9.

Accepted: 3 January 2007 